\title{
THE IMPACT OF TRIPS ON IPRs PROTECTION IN JORDAN, AS A PRIME EXAMPLE OF A DEVELOPING COUNTRY
}

\author{
Mohammad Abdulmahdi Amin Alfaouri \\ Faculty of Law and Political Science, University of Debrecen, Debrecen, Hungary \\ Alfaouri7000@yahoo.com
}

\begin{abstract}
In the last few decades, the developing countries have witnessed a remarkable increase in the infringement of intellectual property rights thus conventions and treaties were held to reduce these infringements, in particular, the TRIPS Treaty (Trade-Related Aspects of Intellectual Property Rights). This study attempts to explain the causes of intellectual property rights infringements and the efficient means for intellectual property rights protections by taking Jordan as an example. The study finds that TRIPS Treaty, which is the latest international action to enhance the protection level, consumer's ethical attitude, development expenditure, economic policies, weakness of law enforcement, and low-income in developing countries are important factors to explain the level of IP protection. Because of all of these, the infringements became a phenomenon in developing countries that firstly need amendments in their intellectual property laws to apply the criminal sanctions jointly by civil remedies, owing to the fact of the shock value or general deterrence to enhance the commitment to the law and to remit this phenomenon, furthermore, the state will follow up on the cost of prosecution without involving the owners of the rights personally in many cases. On the other hand, literature revealed that the infringements of IPRs became a phenomenon because the TRIPS Treaty prepared for the benefits of the large companies, thus the developing countries' legislation, economic and consumer's ethical attitude got affected negatively. In addition, the developed countries threatened them by sanctions if they didn't make retroactively amendments on their legislation, which also led to prevent them to adopt the necessary measures that mitigate the negative impact on their economic and social life. Regarding the applied research method, this paper used secondary data sources and applied the descriptive and comparative analytical legal approaches to illustrate the most important points and findings on the topic.
\end{abstract}

Keywords: TRIPS Treaty, intellectual property rights, infringements, economy.

JEL classification: $\mathrm{K} 2, \mathrm{O} 34, \mathrm{P} 48$.

\section{Introduction}

In today's business environment producers tried to distinguish their commodity from other producer's products to discourage and restrict the efforts of illegal competition practitioners, thus a need was raised for what was later known as the "trademark".

Trademark means the producer turns to put name, word, marks, drawings, design, or symbol, indicating to the goods that belong to the owner of the trademark by the right of manufacturing, producing, trading or selling these goods (Lessig, 2002).

So why the trademark became a place of great interest by many of the world's legislation; and why are laws considering trademarks as valuable assets? for example, France enacted the Trademark Law in 1857, Britain passed the Trademark Law of 1875, the Ottoman Empire enacted the Trademark Law in 1879 which was valid in Jordan until the government passed this law after the independence in 1952 (The Jordanian Trademarks Law No. 33 of 1952). The Intellectual property (IP) laws are considered as a balance between interested parties to achieve their main aims through appropriate procedures and give the owner the 
right to apply a monopoly by using the particular item for a specific period. It is also legal protection for the creators of original work which covers three well-defined sets of rights namely, copyright, trademarks, and patents (Kwanya, 2018). For that, the protection of intellectual property rights (IPRs) has been enforced by treaties such as TRIPS, the latest international action to enhance the protection level to IPRs, which is made to be a part of the World Trade Organisation (WTO) after Uruguay round negotiations.TRIPs provides WTO member countries the right to enforce the IPRs protection over borders with a compulsory framework on the domestic companies (Cardwell and Ghazalian, 2012). Whereby Developing Countries public authorities should comply with their obligations under part III of the TRIPS and put into place compatible with procedures for the effective enforcement of intellectual property rights (Trimble, 2019). In addition, member states of such agreements have to look into difficulties confronting them in the enforcement of intellectual property rights, knowing that, there are several means for enforcement such as investigation, administrative, and judicial enforcement in order to achieve effective and long-lasting for protection (Cafaggi and lamiceli, 2017). However, intellectual property rights are subjected to infringements especially counterfeiting, piracy and contrabands are common occurrences through developing countries like China, where several industries that make goods that appear to be as similar to the original as to be passed off as genuine items and sell the counterfeited goods to the developing countries (Marron and Steel, .2000). Thus, the developing countries have been requested to make retroactively amendments on their legislation because, United States threatened them by sanctions, which led to prevent them to adopt the necessary measures that mitigate from the negative impact on their economic and social life (Correa, 2000).

In Jordan, literature revealed that, there is a weak implementation of enforcement of the IPRs because of the lack of coordination between the various enforcement agencies which claim authority to handle infringements and us extremely reliance on the judicial (criminal and civil) remedies instead of economic solutions which will lead to creating a model concentrate on the introduction of original products, thus undercutting the economic incentive for infringers (Nesheiwat, 2012). Moreover the collectivist cultures in the Arab world, including Jordan, such as cooperation, a sense of belonging to the community, tribe loyalty, solidarity, mutual trust, commitment, and support leads to a weak personal responsibility, limit freedom, less interest about protection for IPRs and share infringements with others who expects you to follow the same actions especially in piracy (Kurman, 2003).

This study intends to shed light on the Islamic law (Sharia) perspective which is totally different from collectivist cultures in the Arab world and its impacts on the consumer's ethical attitude to mitigate the intellectual property rights infringements. As well as discuss the importance of intellectual property rights topics in legal and commercial terms, this study represented the importance of intellectual property rights as a powerful tool for economic growth and their great role in the economic development by encouraging and protecting research and development (R\&D) (Idris, 2002). Also, It focuses and discusses several important topics such as the effects of infringements, evaluation of the TRIPS treaty, counterfeiting on revenue, investment, and employment. Furthermore, the study discusses the causes of the infringement, introduces the audience to new terminologies such as copyright, patent, trademark, piracy, the criminal economy, cultural effect, and impacts on competition. Besides that, this study argues the effectiveness extent of treaties concerned with intellectual property enforcement especially TRIPS agreement, and who is the real winner from its regulations. Lastly, the study attempts to answer the following:

1. What are the causes of intellectual property rights infringements in developing countries?

2. What are the efficient means for intellectual property rights protections? 


\section{Methodologies}

This study is using a descriptive analysis method by reviewing studies that rely on (secondary data) databases to choose several quality studies, which address the topic in a direct way. The data were forty references collected from the Ph.D. dissertations, libraries, thesis, books, articles, and Google Scholar to access the journals. The study has shed a light on the role of determinants in the Intellectual Property Rights Protection according to TRIPs agreement especially Copyright, Patents, and Trademark from an international and national perspective. These studies have analyzed the content in order to achieve the objectives of the study by answering the questions raised in the beginning by dividing the present literature review into three sections as follows:

First: Evaluation of the TRIPS agreement, as the latest international action to enhance the protection level to IPRs, and its impacts on the Member States particularly the developing countries.

Second: The concept of IP protection in Islamic law (Sharia) and its impacts on consumer's ethical attitude and the Arab World legislation including "Jordan" as part of them.

Third: Literature review related to Jordan as a prime example of a developing country to explain the effect of the TRIPs agreement on the efficient of IP law and economic development.

The comparative legal approach will be applied between the above sections and comparison between them to reach the functionalism to find suitable solutions to the study problems.

\section{Literature Review}

\subsection{Evaluation of TRIPS}

The twenty-first century has brought to the Intellectual property rights fundamental changes from the domestic governance to the globe. Consequently, it led up to create global rules to govern intellectual property practices their target. To confirm more protection of intellectual property rights at the expense of more customers access to those rights, TRIPS was made to be a part of the WTO, which was the direct result of huge pressed by companies executives who received full support from the trade negotiators of the advanced countries (Drahos, 2007).

Some scholars like Halbert and Gill adopting resistance of the neoliberal form of globalization, that is the inclusion of the resistance of such forms of commodification as part of the universal fight against IPRs, thence the theoretical criticism of harmonization has increased rapidly, because of the increased of harmonization of IPRs (Gill, 2008; Gurry and Halbert, 2005). In addition, he sees that to protect the types of creative endeavors from the further corrosion of value, that can still be found in women and developing countries produce, we should realize that the real threat occurred by the current commodification of IPRs (Halbert, 2006).

On the other hand, the people will reject the commodification of IPRs because of the main role of IPRs which is concentration on the protection just to increase the prices and focused on the scarcity model, thus led up to a non-efficient model of demand and supply (May, 2015).

Moreover, Braithwaite and Drahos considered that the developing countries have to resist this form of globalization, and they should negotiate and bargaining to adopt a networked governance approach, instead of depending on traditional coalitions-building (Drahos, P. and Braithwaite, 2002). But the Scholars above mentioned, they don't explain that such acts from developing countries will threaten its socio-economic stability because most of them receiving from advanced countries foreign aids which completely relies on it (Matthews, 2003, Sell, 2003, May, 2006). 
Braithwaite and Drahos are also criticized the globally harmonized IP regime, because of the developing countries consider more developed than they are at reality ground. Not only, but also the Developing countries knowing that IP regimes, in general, and TRIPS in particular, not suitable for her technological and scientific capacities, especially the patent systems in TRIPs because they realized that enforcement needs great financial costs (Shadlen, 2008). Besides, TRIPS Treaty imposed the members' countries to set up national IPRs and policies regardless of their social conditions and economic, this could show a diminished difference in their IP laws especially in the validity of intellectual property, which may differ from one country to another. But the variation and flexibility which is available in Paris Convention, for example, giving some countries permissions to establish their patent rules for the Protection of Industrial Property, this flexibility and variation wasn't existence under TRIPS treaty, because it has one enforcement standards, and all the countries members have to follow the same standards (May, 2017).

The advanced countries still practicing great pressures on developing countries particularly after (TRIPS) Agreement to reinforced their intellectual property rights regimes in order to own and achieve more gain from their innovative activity and research. Such protection often needs substantial costs, knowing that, piracy prevents economic growth in developing countries which under pressure made legislative amendments with limited resources (Lee, Alba, and Park, 2018).

Finally, the developing countries according to TRIPS standards made not only immediate amendments for patents law but also, they have been requested to make retroactively amendments on their legislation, otherwise, United States will apply sanctions against them. This request led to prevent them from adopting necessary measures that mitigate the negative impact on their economic and social life (Correa, 2000).

\subsection{IPRs in Islamic law (Sharia)}

The concept of intellectual property was recognized in Arabs societies before Islamic civilization like livestock labeling and poems authors who distribute their poems to have money compensated for their work and they also get protection from society against plagiarism. Further to, this society was familiar with IPRs even though it was rudimentary especially trademark and copyright (Khoury, 2003; Malkawi, 2013).

The purpose behind shedding light on the Islamic law (Sharia) perspective, is to explain their stance from IPRs and its impact on consumer's ethical attitudes in the Islamic world to prevent infringements.

Islamic law (Sharia) has its effective impacts in different degrees on policies and laws in general, especially in the Arab World including "Jordan" as part of them, which refers to (Protecting People's Rights) and prevent the others from stealing the other's effort or use it without permission whether intellectual or material.

Sharia guards the community's interests as well as protecting private property, so it's considered a balanced point stands in the middle between recognizing individual ownership rights and protecting the privileges of society.

Nevertheless, some scholars said that Sharia doesn't regulate the protection directly to the intellectual property rights and doesn't have specific rules such as in the case of inheritance, but the others said that the conclusions and explanations of Sharia principles can provide such protection (Price, 2007). Moreover, the most radical view in Islamic literature that considered the IPRs a tool used by developed countries to acquire benefits instead of the Muslim community (Melhem, Haloosh, and Mahafzah, 2009).

Generally, the majority of Islamic schools (four schools) have accepted the recognition of intellectual property including idea-based property, except "Hanafi" School, which only accepts the tangible property, they justified their view that science and knowledge should be public commodities, and benefit of all humanity including Muslims, thus intangible property can't be compared with industry or trade (Jamar, 1992; Islam, 1999; Raslan, 2006). 


\subsection{Literature Pertaining to Jordan}

In general terms, Intellectual property law consists of several separate and legal disciplines, each with their own terminology. Whereas Copyrights law protects the rights to "original artistic works," including computer software, music, video, architecture, drama, and literature. The Trademarks law protects aspects of branding like symbols, words, and phrases that identify services, companies, and goods. While Patent law protects the rights of the innovation for a limited time determined by law. These include design, plant, and utility. So the infringements mean a work protected by IP laws is copied, used or exploited without having permission from a person who legally owns those rights (Zeidman, 2011).

This types of IP affected by collectivist cultures in the Arab world at the present time, such as cooperation, a sense of belonging to the community, tribal, solidarity, mutual trust, commitment, and support according to the literature perspective and bring many limitations on the self which leads to a weak personal responsibility and limit freedoms.

Therefore Jordan, as part of the Arab world, has the same motivated culture by the above-mentioned factors that lead to less interest in protection for IPRs and share infringements with others and expects them to follow the same actions especially in piracy (Kurman, 2003).

Some scholars like Nowefleh think that foreign direct investment won't flow to Jordan especially in the information technology sector without powerful protection to IPRs (Nawafleh, 2010).

Al Sharari and Sirhan agreed with Nawafleh's opinion that we need more human resources to activate IPRs enforcement in Jordan and unlike that, the weakness of IPRs led to less development research and fewer jobs (Sirhan, 2011; Al Sharari, 2006). But this result emerged without providing us with any basis of such a conclusion from the local context, on the contrary, this conclusion built on foreign reports and foreign scholar's research which discussed the benefits of IP in general instead of the local analysis which shows that there's a little impact of IP laws on foreign investment inflows (Al-Dajani, 2006).

In Jordan, we have a weakly implementation of enforcement of the IPRs because of the lack of coordination between the various enforcement agencies which claim the authority to handle infringements. And also, they extremely reliance on the judicial (criminal and civil) remedies instead of economic solutions which will lead to creating a model concentrate on the introduction of original products thus undercutting the economic incentive for infringers, Nesheiwat finds (Nesheiwat, 2012).

Moreover, behaviors of governmental institutions that are applying the enforcement of IP such as police department, the judicial system, excise agencies, and administration of customs, do not consider IP infringement to be a priority issue thus increase the risks and costs linked with protecting IPRs according to the social behaviors and protocols (Papageorgiadis, and McDonald; 2018; Al-Khashroom, 2002).

Finally, the previous empirical literature found that there is a relationship between income level and the intensity of IPRs protection is U-shaped, for high-income developing countries like Kuwait and Saudi Arabia, these two variables positively impact on their economic development and its companies can engage in their own innovation, but on the contrary, for low-income developing countries like Jordan and Egypt the two variables have a negatively impacted (Hwang, Wu, and Yu, 2016; Huddadeen, 2007).

\section{Discussion and Conclusion}

\subsection{Discussion}

This study attempts to answer the arguments in the manuscript according to the literature review and the implementation of IPRs in Jordan as a prime example of a developing country which shows that: 
(A)TRIPS agreement imposed the member's countries to set up national IPRs policies according to the 'one-size-fits-all' standard, in spite of developing countries consider it as a rent collection device with potentially bad effects on public health, economic development and education in the majority of them. So according to many scholars like Halbert and Gill who adopting resistance of the neoliberal form of globalization that is the inclusion of the resistance of such forms of commodification as part of the universal fight against IPRs.

Also, May (2015) sees that concentration on the IPRs protection only for a certain aim which is increasing prices, as a result of the role of IPRs which is focused on scarcity model that led up to a non-efficient model of demand and supply.

Moreover, Braithwaite and Drahos consider that the developing countries have to resist this form of globalization, and these countries shouldn't depend on traditional coalition-building, instead of that they should be negotiating and bargaining to adopt a networked governance approach (Braithwaite and Drahos, 2002).

In addition, Shadlen (2008), Lee Park and Alba (2018) said that TRIPS do not suitable for Developing countries' technological and scientific capacities, especially the patent systems in TRIPs because they are realizing that enforcement needs great financial costs and piracy in specific (Piracy prevent economic growth in developing countries).

(B) Regarding to the second argument in the manuscript, which indicated the inefficient enforcement of the domestic laws in developing countries, resulting in the absence of the shock value that advances the commitment to the law, scholars like Nawafleh who think that foreign direct investment won't flow to Jordan especially in the information technology sector without powerful protection to IPRs.

Also, Al Sharari (2006) and Sirhan (2011) opinion that we need more human resources to activate IPRs enforcement in Jordan. unlike that, the weaker IPRs led up to less development research and fewer jobs. Moreover Nesheiwat (2012) thinks that in Jordan we have a weakly implementation of enforcement of the IPRs because of the lack of coordination between the various enforcement agencies which claim authority. In addition, Al-Khashroom (2002) said that the behaviors of governmental institutions that are applying the enforcement of IP such as police department, the judicial system, excise agencies, and customs do not consider IP infringement to be a priority issue thus increase the risks and costs linked with protecting IPR according to the social behaviors and protocols.

Without a doubt, Jordan is one of the low-income countries because of its heavily dependent on foreign aid which comes from the donors who in turn imposed the legal guidelines of IPRs and also the economy could not go far without fundamental input from multinational companies(foreigners) who are the suppliers of innovation and knowledge,so the economy had been affected negatively (Huddadeen, 2007). Finally, Kurman (2003) said that the collectivist cultures in the Arab world at the present time, bring many limitations on the self which leads to a weak personal responsibility and limit freedoms. Therefore Jordan, as part of the Arab world, has the same motivated culture that leads to less interest in protection for IPRs and shares infringements with others and expects them to follow the same actions, especially in piracy.

\subsection{Conclusion}

Our findings indicate that the causes of IPRs infringements related to many reasons, one of them is TRIPS agreement which is received many criticisms in the effectiveness and legitimacy especially in developing countries who consider it a rent collection device, with potentially bad effects on public health, economic development, and education in the majority states.

Moreover, the advanced countries like the United States threatened developing countries by sanctions if they didn't make retroactively amendments on their legislation according to TRIPS agreement standards, this request led to prevent them from adopting necessary measures to mitigate the negative impact on their economics and social life. 
Furthermore, the benefits of TRIPs agreement and its function are not as they advertised, because it is targeting particular sections of society in those countries who appear to win most from it, for that, the large corporations practiced great pressure to adopt this agreement because they are the real winners from TRIPS.

Obviously, the TRIPS agreement prepared in a way that is believed to achieve the interests of all signatory States and to achieve free trade and technology diffusion, for that, TRIPS set the minimum protection standards that member states must adhere to and gave the members full free to adopt higher standards to mark the scope of protection if it was to their benefit. But when we look at the way that TRIPS agreement was prepared we note that, it did not come with radical changes in the intellectual property rights protection system which was prevalent before it, but rather by, the authors combined previous agreements and treaties with some addition such as amendments in the minimum protection periods for different forms of intellectual property and Provided TRIPS with a dispute settlement mechanism. In addition, the empirical literature found that there is a relationship between income level and the intensity of IPRs protection is U-shaped, for low-income developing countries these two variables negatively impact economic development.

Based on the above, the gross domestic product per capita in developing countries (low-income), economic policies, weakness of law enforcement, behaviors of governmental institutions that applying the enforcement of IP who do not consider IP infringement to be a priority, and the consumer's ethical whom affected by the collectivist cultures at the present time (share infringements with others and expects them to follow the same actions especially in piracy) are important factors to explain the weakness level of IP protection.

Finally, the intellectual property law needed to apply the criminal sanctions in conjunction with civil remedies owing to the fact of the shock value or general deterrence to enhance the commitment to the law, hence extended to the liability of the corporates in both developing and developed countries. In addition, the State will follow up on the cost of prosecution without involved the owners of the rights personally in many cases.

\section{Final discussion}

The IP law in Jordan has been built like many developing counters under the pressure of the advanced countries and donors thus the impact on the economy nominally because it's not suitable for economic development but just protects the interests of the foreign corporations, moreover, it's not fit with Jordanian culture because they are unable to touch the results for their economic benefits.

Clearly, to rectify the gaps in IP law in Jordan it's important to discuss IPRs from a localized analysis approach instead of a global perspective to achieve reducing tension between the competitiveness social objectives and admitting private rights to support innovation, then this understanding can be used to Impact on the discussion of trade agendas and international IP. Also, it would have been more harmonizing from a global perspective to adopt a tiered system, offering more differential treatment and substantial according to the countries' needs and developmental, instead of adopting a 'one-size-fits-all" definitely inappropriate.

Not only but also, the application of criminal sanctions strictly will achieve two things, firstly, preventing the rights holders from attempting to extend their rights behind the terms of the grant, secondly, preventing the imitators from infringements.

\section{References}

Al Sharari, S., 2006. Intellectual Property Rights Legislation and Computer Software Piracy in Jordan. Journal of Social Sciences, 2 (1), pp.7-13. 
Al-Dajani, E.M., 2006. Post Saddam restructuring of intellectual property rights in Iraq through a case study of current intellectual property practices in Lebanon, Egypt, and Jordan. The John Marshall Review of Intellectual Property Law, 6, pp. 250-271.

Al-Khashroom, A., 2002. The Effect of Jordan's Accession to the WTO in Jordanian Industrial and Commercial Property Legislations. Law Journal, Al-Kuwait University, 26 (2), pp. 5-13.

Cafaggi, F. and lamiceli, P., 2017. The principles of effectiveness, proportionality and dissuasiveness in the enforcement of EU consumer law: The impact of a triad on the choice of civil remedies and administrative sanctions. European Review of Private Law, 25 (3), pp. 575-618.

Cardwell, R. and Ghazalian, P.L., 2012. The effects of the TRIPS agreement on international protection of intellectual property rights. The International Trade Journal, 26 (1), pp. 19-36 Correa, C.M., 2000. Intellectual property rights, the WTO and developing countries: the TRIPS agreement and policy options. London: Zed Books.

Drahos, P. and Braithwaite, J., 2002. Information feudalism: Who owns the knowledge economy? Earthscan.

Drahos, P., 2007. Four lessons for developing countries from the trade negotiations over access to medicines. Liverpool Law Review, 28 (1), pp.11-39.

Gill, S., 2008. Power and resistance in the new world order. New York: Palgrave Macmillan. Gurry, F. and Halbert, D., 2005, March. Globalization, development, and intellectual property: New challenges and new opportunities. In Proceedings of the Annual Meeting (American Society of International Law), pp. 291-300.

Halbert, D., 2006. Feminist interpretations of intellectual property. American University Journal of Gender. Social Policy and the Law, 14, pp. 431-460.

Huddadeen, A.B, 2007. The Effect of The Agreement on Trade-Related Aspects of Intellectual Property Rights" TRIPS" on the Jordanian Economy. Master Thesis, Al al-Bayt University, Malfraq, Jordan.

Hwang, H., Wu, J.Z. and Yu, E.S., 2016. Innovation, imitation and intellectual property rights in developing countries. Review of Development Economics, 20 (1), pp.138-151.

Idris, K., 2002. Intellectual property: a power tool for economic growth, Vol. 888. WIPO.

Islam, M.W., 1999. Al-Mal: The concept of property in Islamic legal thought. Arab Law Quarterly, 14 (4), pp.361-368.

Jamar, S.D., 1992. The protection of intellectual property under islamic law. Cap. UL Rev., 21, p.1079.

Khoury, A.H., 2003. Ancient and Islamic Sources of Intellectual Property Protection in the Middle East: A Focus on Trademarks. IDEA, 43, p.151.

Kurman, J., 2003. Why is self-enhancement low in certain collectivist cultures? An investigation of two competing explanations. Journal of Cross-Cultural Psychology, 34 (5), pp. 496-510.

Kwanya, T., 2018. Social Bookmarking in Digital Libraries: Intellectual Property Rights Implications. In Handbook of Research on Managing Intellectual Property in Digital Libraries (pp. 1-18). IGI Global.

Lee, M., Alba, J.D. and Park, D., 2018. Intellectual property rights, informal economy, and FDI into developing countries. Journal of Policy Modeling, 40 (5), pp.1067-1081.

Lessig, L., 2002. The future of ideas: The fate of the commons in a connected world. New York: Random House Inc.

Malkawi, B.H., 2013. Intellectual property protection from a Sharia perspective. Southern Cross University Law Review, 16, pp. 87-122.

Marron, D.B. and Steel, D.G., 2000. Which countries protect intellectual property? The case of software piracy. Economic Inquiry, 38 (2), pp.159-174.

Matthews, D., 2003. Globalising intellectual property rights: the TRIPS Agreement. Routledge. 
May, C., 2006. World Intellectual Property Organization (WIPO): Resurgence and the Development Agenda. Routledge.

May, C., 2015. The global political economy of intellectual property rights: The new enclosures. Routledge.

May, C., 2017. Why IPRs are a global political issue. In Globalization and Intellectual Property (pp. 21-25). Routledge.

Melhem, B., Haloosh, H. and Mahafzah, Q.A., 2009. The perspective of moral and financial rights of intellectual property in Islam. Arab Law Quarterly, 23 (4), pp.457-468.

Nawafleh, A., 2010. Development of intellectual property laws and foreign direct investment in Jordan. Journal of International Commercial Law and Technology, 5 (3), pp.142-153.

Nesheiwat, F., 2012. The Compliance with Intellectual Property Laws and their Enforcement in Jordan-A Post-WTO Review \& Analysis (Doctoral dissertation, Durham University, U.K.). Papageorgiadis, N. and McDonald, F., 2018. Defining and Measuring the Institutional Context of National Intellectual Property Systems in a Post-TRIPS World. Journal of International Management. 25 (1), pp. 3-18.

Price, D., 2007. The Dynamics of intellectual property protection in the Arab Gulf states. International Review of Business Research Papers, 3(1), pp.147-161.

Raslan, H.A., 2006. Shari'a and the Protection of Intellectual Property - the Example of Egypt. IDEA, 47.

Sell, S.K., 2003. Private power, public law: the globalization of intellectual property rights, Vol. 88. Cambridge University Press.

Shadlen, K.C., 2008. Policy space for intellectual property management: Contrasting multilateral and regional-bilateral arrangements. Revista Econômica, 10 (2), pp. 55-81.

Sirhan, A.A., Intellectual Property and Copyright Laws and Their Impact on Digital Resources in Jordan (May 2011), pp.7-13. [online], available at: http://www. informationstudies. net/issue list. php. [Accessed 04.02. 2019].

The Jordanian Trademarks Law and its amendments No. 33 of 1952.

Trimble, M., 2019. Enforcement of Intellectual Property Rights at Trade Shows: A Review and Recommendations. Scholarly Works. 1263. [online], available at: https://scholars.law.unlv.edu/facpub/1263, [Accessed 04.02. 2019].

Zeidman, B., 2011. The Software IP Detective's Handbook: Measurement, Comparison, and Infringement Detection. Prentice Hall Professional.

\section{Bio-note}

Alfaouri Mohammad is a Ph.D. candidate at the Faculty of Law and Political Science, University of Debrecen, Hungary, and member of the several research teams developed within the projects implemented by our Faculty. Alfaouri as a researcher interested in intellectual property rights (IPRs) protection and its impact on the developing countries legislation and economics and conducted many types of research focused on intellectual property rights (IPRs). 